Article

\title{
An Autonomous Wireless Health Monitoring System Based on Heartbeat and Accelerometer Sensors
}

\author{
Saif Saad Fakhrulddin ${ }^{1,2}$ and Sadik Kamel Gharghan ${ }^{1, *(D)}$ \\ 1 Department of Medical Instrumentation Techniques Engineering, Electrical Engineering Technical College, \\ Middle Technical University, Baghdad, Iraq \\ 2 College of Dentistry, University of Mosul, Mosul, Iraq \\ * Correspondence: sadik.gharghan@mtu.edu.iq; Tel.: +964-7736393936
}

Received: 29 May 2019; Accepted: 10 July 2019; Published: 13 July 2019

\begin{abstract}
Falls are a main cause of injury for patients with certain diseases. Patients who wear health monitoring systems can go about daily activities without limitations, thereby enhancing their quality of life. In this paper, patient falls and heart rate were accurately detected and measured using two proposed algorithms. The first algorithm, abnormal heart rate detection (AHRD), improves patient heart rate measurement accuracy and distinguishes between normal and abnormal heart rate functions. The second algorithm, TB-AIC, combines an acceleration threshold and monitoring of patient activity/inactivity functions to accurately detect patient falls. The two algorithms were practically implemented in a proposed autonomous wireless health monitoring system (AWHMS). The AWHMS was implemented based on a GSM module, GPS, microcontroller, heartbeat and accelerometer sensors, and a smartphone. The measurement accuracy of the recorded heart rate was evaluated based on the mean absolute error, Bland-Altman plots, and correlation coefficients. Fourteen types of patient activities were considered (seven types of falling and seven types of daily activities) to determine the fall detection accuracy. The results indicate that the proposed AWHMS succeeded in monitoring the patient's vital signs, with heart rate measurement and fall detection accuracies of $98.75 \%$ and $99.11 \%$, respectively. In addition, the sensitivity and specificity of the fall detection algorithm (both $99.12 \%$ ) were explored.
\end{abstract}

Keywords: accelerometer sensor; fall detection; GSM; GPS; healthcare; heartbeat sensor; smartphone

\section{Introduction}

The technology of transferring data on the vital signs of a patient through a wireless body area sensor network (WBSN) has become a widely used technique [1]. Some patients have diseases (e.g., heart arrhythmia, angina, heart blockage, loss of balance) or other factors that may cause falls and fainting. Therefore, these patients may need prompt first aid or transportation to the hospital. To meet this need, a vital signs monitoring system (VSMS) can be used to monitor patients using sensors, such as a heartbeat sensor (HB) and accelerometer sensor (ACC) [2] (for abbreviations, see Appendix A). HB and ACC sensors are used to measure heart rate (HR) and fall detection (FD), respectively. These sensors are connected to some nodes on the body, called sensor nodes, to collect the patient's parameters [3]. The output data from the sensor nodes can be sent to the central station of the VSMS via router nodes based on wireless technologies, such as Global System for Mobile Communications (GSM), ZigBee, and Bluetooth [4]. The central station receives the signals, then processes and displays them and makes a decision. When the parameters of the patient indicate abnormal conditions, the central station will inform the caregivers at a medical emergency call center (MECC) to send first aid to the patient [5].

Recently, the design and development of VSMSs has been a topic of strong interest for researchers. Two important parameters for these systems, HR and FD, have been considered in previous works [6-14]. 
Researchers have designed a wearable VSMS to distinguish between activities of daily living (ADL) and accidental falls using classification algorithms. In addition, previous studies have evaluated the accuracy of this classification as well as that of HR, electrocardiogram (ECG), and oximeter saturation (Spo2) measurements. In this paper, a new algorithm is proposed that utilizes two parameters-acceleration threshold and patient activity level—to classify activities as either ADL or a fall. The proposed device can be used both indoors and outdoors and achieves a long wireless transmission distance by using a mobile GSM network. To evaluate the proposed device, this work also uses a commercial fingertip heart rate monitor as a benchmark (BM) system. In this study, the HR measurement accuracy of the AWHMS was validated relative to the measurement obtained by the BM system. Validation was performed using statistical analyses, such as the mean absolute error (MAE), correlation coefficient, and Bland-Altman plots. In addition, FD was validated according to a proposed algorithm for the classification of 14 activities (including seven types of falls and seven ADLs), and the accuracy, sensitivity, and specificity of classification were calculated for the evaluated activities $[15,16]$.

In this study, an autonomous wireless health monitoring system (AWHMS) based on GSM wireless technology is proposed for monitoring the HR and FD parameters of patients. GSM wireless technology is used in the proposed device because it has a long wireless transmission distance and uses mobile networks [17-19]. Three main operations-parameter measurement, data processing, and decision-making if a parameter value is abnormal—can be performed autonomously by the proposed AWHMS. The proposed AWHMS utilizes two algorithms. First, the abnormal heart rate detection (AHRD) algorithm detects abnormal HR measurements. Second, the threshold based and activity/inactivity counter (TB-AIC) algorithm detects falls. Third, in the event of an abnormal parameter value, the AWHMS device will send a message via the GSM module to the MECC; the message can include patient location information (latitude and longitude) for outdoor environments based on the GPS module. The MECC caregivers will use the transmitted information about patient status and geographic location to send first aid to the patient in critical cases [20].

The contributions of this paper can be summarized as follows:

(i) A new design of a wearable AWHMS is presented based on a WBSN with high measurement accuracy and a long communication range based on the GSM network.

(ii) The accuracy of patient heart rate measurement was improved, and the normal and abnormal patient heart rate functions were identified based on the abnormal heart rate detection (AHRD) algorithm.

(iii) Patient falls were accurately detected based on a new proposed algorithm that combines an acceleration threshold and activity/inactivity counter (TB-AIC).

(iv) The performance of heart rate measurement and fall detection was confirmed based on statistical analysis.

(v) The results of the current work were compared with those of similar previous studies in terms of accuracy, sensitivity, and specificity to validate the performance of the proposed AWHMS.

\section{Related Work}

A number of previous works have proposed wearable devices for patient fall detection that have adopted different algorithms or techniques. These works have proposed systems for monitoring patient vital signs, such as heart rate, temperature, Spo2, and ECG. For example, Wang et al. [6] developed a health monitoring system that can measure human vital signs. The monitoring system may be used for FD, elderly care, postoperative care, rehabilitation, sports training, and other applications. The authors adopted a coupled hidden Markov model (CHMM) to recognize human activities. Three nodes collected ECG, Spo2, and motion signals. Then, the gathered signals were transmitted wirelessly based on ZigBee (XBee S2) to the receiving node, which in turn analyzed the signals in real time using software written in $\mathrm{C}++$. The experimental results show that the system can wirelessly transmit data up 
to $20 \mathrm{~m}$ indoors and $100 \mathrm{~m}$ outdoors. In addition, the CHMM classifier achieved an average recognition accuracy of $94.8 \%$, with ECG and Spo2 measurement accuracies of $88.75 \%$ and $83.75 \%$, respectively.

Kańtoch et al. [7] implemented a wearable health monitoring system based on a wearable body sensor network for tracking and analyzing human physiological signals. The authors examined WBSN measurements according to a research scenario, including common daily activities, such as working, resting, walking in different directions, and physical exercise. The experimental results showed a 95\% classification accuracy for these activities. Meanwhile, Kakria et al. [8] developed a health monitoring system for remote cardiac patients based on advanced wireless and wearable sensor technologies. The aim of the project was to facilitate the provision of the latest healthcare services to remote cardiac patients. The authors proposed a location-based real-time monitoring system comprising a wearable sensor based on WBSNs, a smartphone, and a web interface for monitoring. The system detects abnormal health measurements, such as arrhythmia, hypotension, hypertension, fever, and hypothermia, and sends alerts to the patient monitoring center in less time than other devices with an accuracy of more than $90 \%$.

Cheng et al. [9] proposed a new method for daily activity monitoring and FD based on surface electromyography (SEMG) and ACC. The authors adopted a histogram negative entropy algorithm to determine the start and end points for static and dynamic active segments and double stream hidden Markov models (HMM) to identify dynamic gait activities. The results showed that the daily activity monitoring and FD scheme achieved a recognition accuracy of over $98 \%$. Advantages of the proposed method include its low computational cost and the ability to accurately distinguish normal dynamic transition activities and falls. However, the proposed method might not detect some specific fall types, e.g., a faint from a seated posture or a fall from the bed while sleeping.

Sikder et al. [10] introduced a new way to measure the distance between sequences of numbers and applied it to identify human activities based on wearable motion sensors. The proposed method can be used to solve detection rate problems, and the resulting activity classification rate is better than those based on other methods, such as Kullback-Leibler (KL)-distance and angle similarity. The authors adopted a new distance measurement based on a log-sum distance algorithm. The results showed that the proposed algorithm can be used to (i) detect all activities with a $99 \%$ accuracy and (ii) decrease misclassification by computing optimal threshold values and using them to classify activities. Gia et al. [11] presented a new system for FD monitoring of an elderly person based on a wearable body sensor. The aim of the project was to investigate the energy consumption of sensor nodes in an internet-of-things-based FD system and present a design for a customized sensor node. The authors compared customized sensor nodes with other sensor nodes built on general purpose development boards. Bluetooth low energy was adopted as the wireless technology. The results showed that the proposed sensor node with energy efficiency selections can operate continuously for up to $35 \mathrm{~h}$. The proposed sensor nodes based on customized devices were more energy efficient than those based on general purpose devices despite having identical micro-controller and memory capacity specifications. Aguiar et al. [12] presented a new method for FD and ADL of an elderly person based on a smartphone. They used data from the smartphone's built-in ACC as input to a state machine algorithm that recognizes the stages of a fall in sequential order. The system consists of a Samsung Galaxy Nexus Smartphone that includes an ACC sensor for FD, GPS to send location, and an alarm for when a fall occurs. From the results, the accuracy of the FD algorithm proposed by Aguiar et al. was near $97.5 \%$ for both pocket and belt usage. One advantage of their method was an increased reliability for detecting fall events without disturbing the users with excessive false alarms.

Dapri et al. [13] developed an algorithm for respiratory rate measurement based on WBSNs and a smartphone. The aim of the project was to avoid the superfluous duplication of resources and exploit the relatively high computational capabilities available in smart devices for local preliminary processing. The authors adopted an ECG-derived respiration algorithm for respiratory rate measurement and used a smartphone for processing. Experimental tests conducted using smartphone technology confirm the feasibility of the proposed approach, with a precision of greater than $90 \%$. The proposed system has 
some advantages, such as avoiding the duplication of computational units by moving all processing effort into the smartphone and limiting the raw body motion data required by the algorithm, which makes it possible to simplify the wearable sensor. Finally, Wu et al. [14] developed a novel system for FD for elderly patients based on WBSNs. The authors adopted an algorithm for fall detection based on thresholds of the sum acceleration and rotation angle. The system adopted a GSM/GPRS module based on Subscriber Identity Module (SIM908) as the wireless technology. The test results showed suitable sensitivity and specificity levels of $97.1 \%$ and $98.3 \%$, respectively. The advantages of their system include low power consumption and a highly efficient algorithm.

Previous related work has presented some limitations related to measurements and classifications that pose challenges in a VSMS, such as low measurement accuracy for HR, SpO2, and ECG. In addition, previous classification algorithms developed to distinguish between ADL and FD have exhibited lower performance in terms of accuracy, sensitivity, and specificity. Moreover, some of these studies have adopted wireless technologies with short transmission distances, such as ZigBee, Bluetooth, and Wi-Fi, which restricts the movement of the patient within their indoor environment. In addition, the patient's outdoor movement is limited to the proximity of their house. These obstacles motivated us to design and develop a prototype based on the WBSN that can be used for the measurement and classification of vital signs with high accuracy.

The most important vital signs utilized in the related works summarized above are HR, FD, SpO2, and ECG [6-14,21]. HR and FD are the most significant signals considered in this work. The sensor locations used most frequently in those previous works have been the wrist [6], belt [14], chest [8], ankles [10], leg [9], and waist [22]. The upper arm was not adopted as a sensor location in these previous articles but was considered in our study, as this location provides less sensitivity to natural body movements for the acceleration sensor. In addition, the outer skin layer of the upper arm location is more suitable and has a higher conductivity than the other locations for HR monitoring. As reviewed above, previous work has adopted algorithms for distinguishing between ADL and FD, such as CHMM [6], support vector machine (SVM) [11], state machine [12], and threshold of sum acceleration $[7,14]$ algorithms. In the current work, we propose a new algorithm (i.e., TB-AIC) that can achieve high fall detection accuracy. In addition, the proposed AHRD algorithm detects abnormal HR with a high measurement accuracy relative to the previous studies.

\section{System Architecture}

Figure 1 shows a block diagram of the whole AWHMS, which consists of two parts. The first part is a wearable transmitter node, as shown in Figure 1a. The transmitter node consists of two sensors (HB and ACC), an Arduino Pro mini microcontroller, a GPS module based on Ublox M8N, a GSM module based on SIM8001, and a power supply based on two parallel lithium-ion batteries $(3.7 \mathrm{v} / 8400 \mathrm{mAh})$ [23]. All components of the transmitter node were carefully selected to limit its power consumption, weight, and size and to ensure its durability.

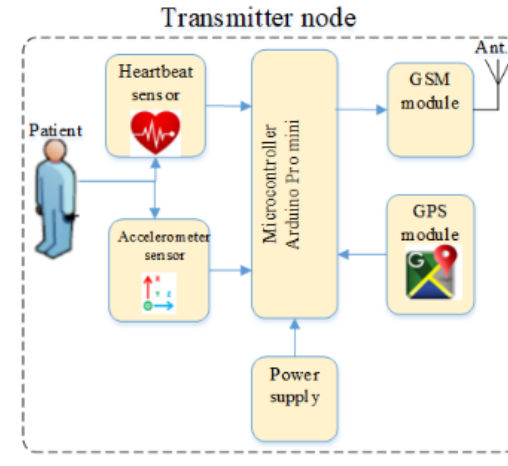

(a)

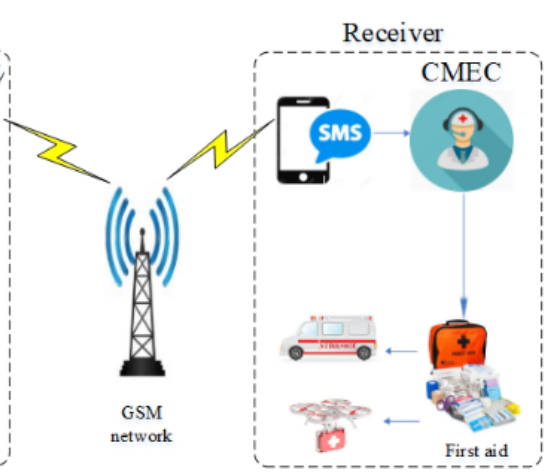

(b)

Figure 1. Block diagram of the proposed AWHMS, including (a) the transmitter node and (b) receiver. 
The second part of the AWHMS, shown in Figure 1b, is the receiver of the AWHMS and includes a smartphone device, the MECC, and first responders [24,25]. Based on the proposed AWHMS, the patient can be monitored everywhere and at all times outdoors. The AWHMS can utilize the infrastructure of the GPRS/GSM network, which is frequently available at every location in the world. The patient's status can be viewed by their doctor on a mobile device. A MECC can also send first aid to the patient in emergency cases based on emergency medical services, such as an ambulance or drone.

\subsection{Hardware of AWHMS}

The proposed AWHMS consists of the electronic components described below:

\subsubsection{Accelerometer}

Accelerometer sensors are widely used for patient fall detection [11,14,26,27]. The digital ADXL345 sensor has several desirable properties, such as being small, thin dimensions, and ultralow power usage. It is a 3-axis accelerometer with high resolution (13-bit) measurement up to $\pm 16 \mathrm{~g}$ and a high resolution $(3.9 \mathrm{mg} / \mathrm{LSB})$ for dynamic acceleration during motion. The digital output data are formatted as 16-bit twos complement values. Several special sensing functions are provided by the ADXL345, such as activity and inactivity detection, where the presence or absence of motion is determined based on the acceleration on any axis. In addition, the ADXL345 is used for free-fall detection based on user-set thresholds [28].

The ADXL345 can be powered by Direct Current (DC) voltage from the $3.3 \mathrm{~V}$ pin of the microcontroller. The data recorded by the ACC sensor are transferred to the microcontroller via the SDA and SDL pins through a serial digital interface (SPI). The microcontroller processes the received data to extract the $x$-axis, $y$-axis, and $z$-axis accelerations. The values of these axes can be utilized to calculate the sum magnitude vector (SMV) [29]. The ACC sensor adopted in this paper was selected to take advantage of its internal sensing functions (activity, inactivity, and free-fall) and to utilize the SMV to improve the proposed algorithm for FD.

\subsubsection{Heartbeat Sensor}

Heart rate sensors have been incorporated into some previous work $[2,6,15,30]$ to assess patient health. The working principle of the HB sensor is photoplethysmography (PPG). PPG utilizes a high-precision light sensor to detect the volume of blood flow in order to observe HR. The HR can be recognized by measuring the changes in the intensity of the light passing through capillary blood vessels depending on the light absorption. An HB sensor is a non-invasive sensor, meaning no insertions into the body. The HB sensor consists of a transmitter light generated by a green light emitting diode (LED), a reflective sensor based on a photo detector, an optical filter, and a power supply board. An optical filter pulse is used to minimize the effects of ambient light, such as red and infrared rays [18]. This enables high-quality pulse signals to be acquired, even indoors and outdoors. The low brightness of the LED used makes it possible to achieve a low-power HR monitoring system without the need for a boost circuit. In addition, this contributes to longer operating times in a wearable device with a limited battery capacity.

\subsubsection{Microcontroller}

The Arduino Pro Mini board based on an ATmega328P microcontroller [31] was used as the microcontroller board in the proposed AWHMS. It has 14 digital input/output pins (6 pins can be used as PWM outputs), 6 analog inputs, an on-board resonator, a reset button, and holes for mounting pin headers. The microcontroller supports six pin headers for connection to a Future Technology Devices International (FTDI) cable to provide USB power and communication to the board with a $3.3 \mathrm{~V}$ voltage regulator. The ATmega328P is programmed using $\mathrm{C}++$. Some off-the-shelf libraries can be adopted with some modifications to improve measurement performance and support the system's successful 
use [32]. In this work, microcontroller programming performs three main activities: Monitoring, processing, and making a decision. First, the microcontroller processes the data received from the HR and ACC sensors via the serial port at a rate of $9600 \mathrm{kbps}$. Then, the microcontroller monitors the vital sign parameters of the body for abnormalities in the received data. Finally, in the event of a detected abnormality, the microcontroller will acquire the patient's location from the GPS module via the serial port (Rx) at a rate of $9600 \mathrm{kbps}$, and then send an SMS message to the MECC through the GSM module via the serial port (Tx) at $4800 \mathrm{kbps}$. The SMS message includes the patient's status and geographic location [30].

\subsubsection{GSM Module and Smartphone}

In the current work, the SIM800L board was adopted as the GSM module for sending the SMS message to the MECC. The SIM800L is a digital cellular technology used for transmitting mobile voice and data services. It has some properties that differ from other types of GSM modules, such as its small size, $2 \mathrm{G}$ (second generation of cellular technology) quad-band at the 850/900/1800/1900 MHz frequency bands, and compatibility with smartphones, PDAs, and other mobile devices [33].

In this study, the GSM module was programmed in $\mathrm{C}++$ using the AT command to connect the adopted SIM chip to the local GSM network, which has a good transmission signal, as shown in Figure 2. The GSM receives data from the microcontroller via the serial port at $4800 \mathrm{kbps}$. Then, the GSM transmits an SMS that includes the patient's information (patient ID, health status, and geographic location) via the GSM network to a receiver device located in the MECC, such as a smartphone [19,34]. A smartphone (iPhone 7 device) was used in the MECC to receive the SMS sent from the GSM module of the transmitter of the AWHMS. The SMS message includes the patient's status and location in the form of a Google Maps URL. This link is easy for a smartphone to handle. In addition, there is no need for any complex program to decode the data [34].

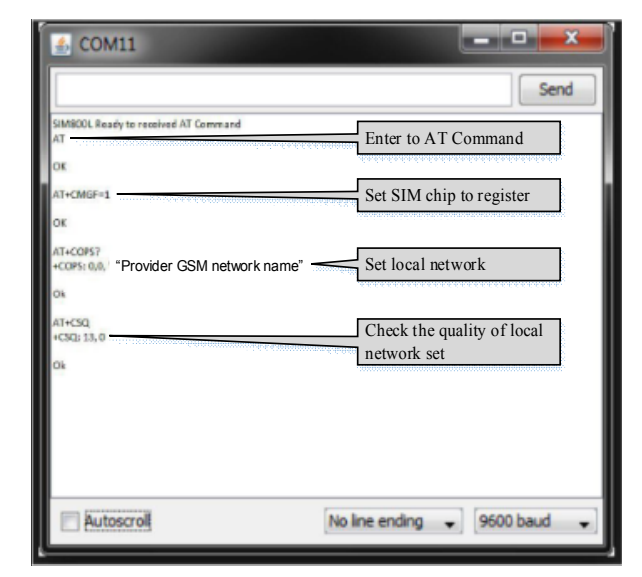

Figure 2. Serial monitor window with ATtention (AT) commands of the Arduino integrated development environment (IDE) compiler.

\subsubsection{GPS Module}

A UBLOX M8N board was adopted as the GPS module in the current work [35]. It has several benefits, such as concurrent reception of up to 3 Global navigation satellite system (GNSS) (GPS, Galileo, GLONASS, Badious), $-167 \mathrm{dBm}$ navigation sensitivity, security and integrity protection, support for all satellite augmentation systems, and advanced jamming and spoofing detection [36]. The UBLOX M8N acquires the patient's location (latitude and longitude) and sends the coordinates to the microcontroller at a rate of $9600 \mathrm{kbps}$ [37] in real time. 


\subsection{Proposed Algorithm}

Three significant aims were achieved in this work. The first was the initialization and calibration of the system. The second was the development of the proposed algorithm for the detection of an abnormal measured heart rate, called AHRD. The third was the development of the proposed algorithm for fall detection based on a hybridization of the falling acceleration threshold and activity/inactivity internal functions of the ACC sensor, called the threshold-based and activity/inactivity counter (TB-AIC) algorithm.

The proposed algorithms and initialization and calibration functions are performed by the ATmeg328P microcontroller chip. The microcontroller starts by defining all variables, setting up the input/output (I/O) pins, and begins to receive data from the HB and ACC sensors. The HB sensor has a major problem in that after startup, it does not accurately measure HR until it reaches a steady state (measures the highest or lowest values of HR), which can take between 7 and $60 \mathrm{~s}$ of operating time. Most previous studies have not considered this HB sensing problem in the design of the VSMS. In fact, this problem has affected the accuracy of HR measurements in previous work.

In this study, the HB sensor problem was resolved by adopting a calibration algorithm. Figure 3 shows the difference between the proposed device and a BM for $100 \mathrm{HR}$ measurements. When a calibration algorithm is not used, as shown in Figure 3a, measurements 1 to 41 of the proposed AWHMS exhibit overshooting, abnormality, noise, and poor accuracy for HR measurement compared to measurements 42 to 100 . Figure $3 b$ shows the effect of the calibration algorithm; measurements 1 to 60 were more accurate and less noisy.

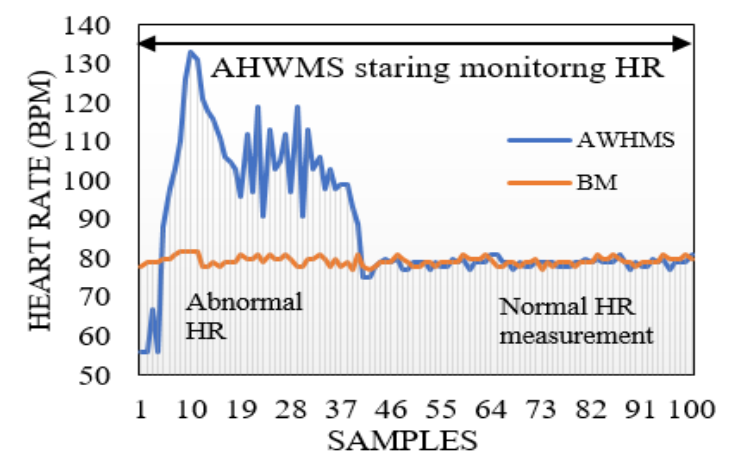

(a)

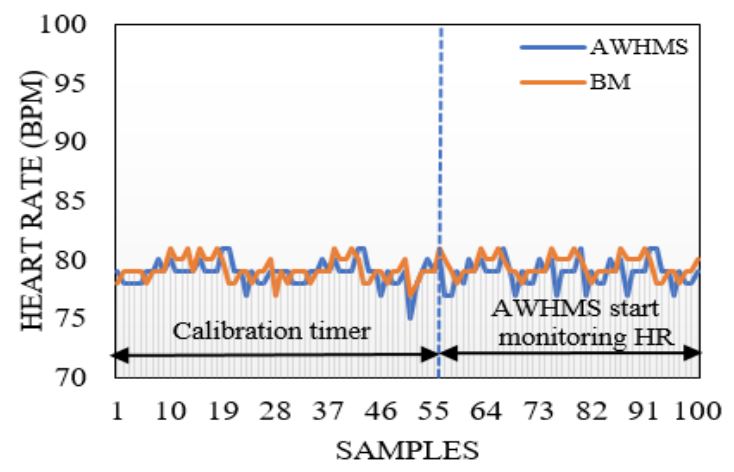

(b)

Figure 3. HR settling time (a) without the calibration algorithm and (b) with the calibration algorithm.

After complete calibration of the HB sensor as shown in Figure 4a, the AWHMS begins to monitor $\mathrm{HR}$ and FD. If an abnormal HR measurement is detected based on the AHRD algorithm or a fall detection is indicated by the TB-AIC algorithm, the microcontroller will send a message to the MECC via the GSM module. These algorithms are explained below: 


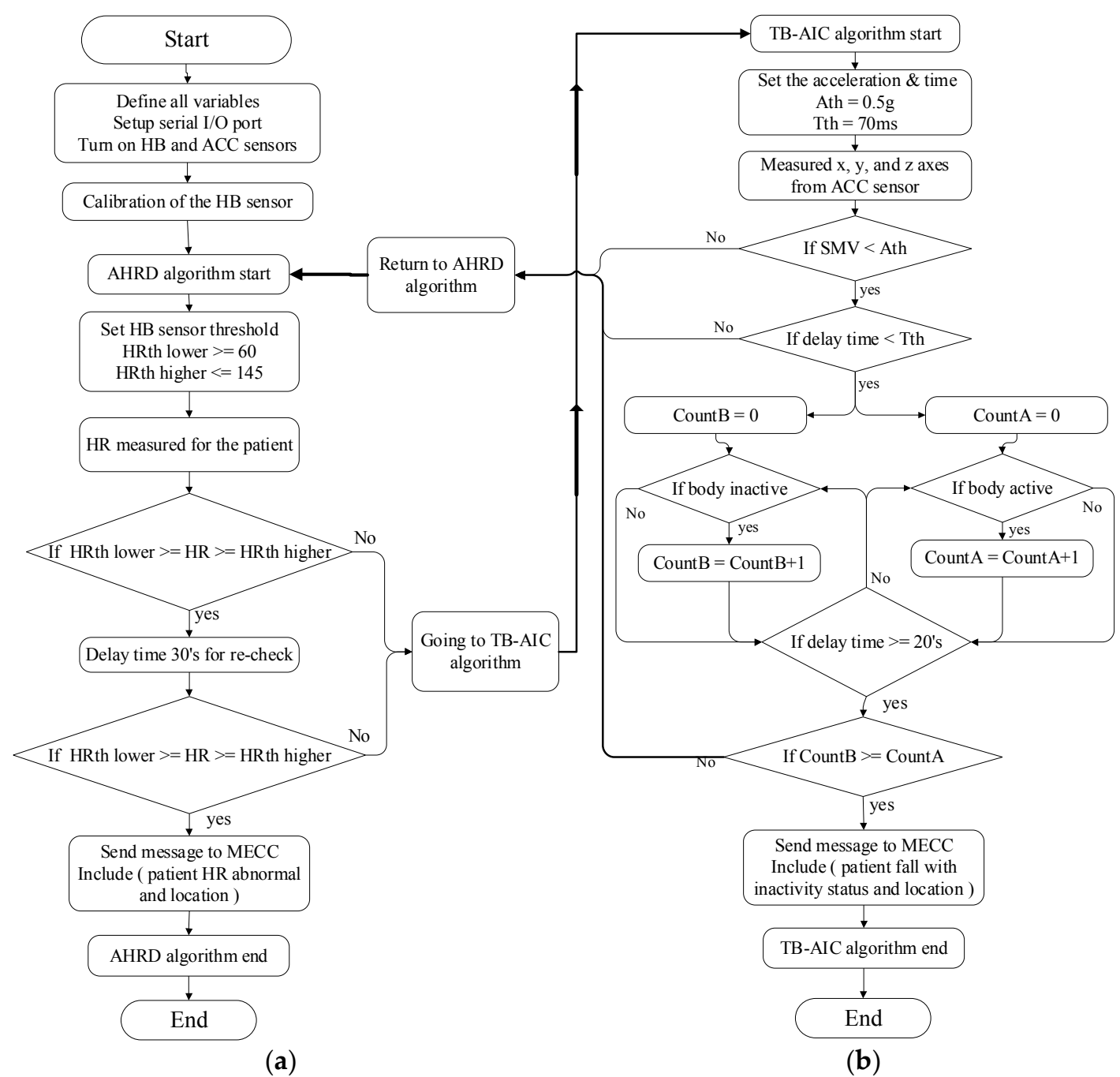

Figure 4. Flow chart of the AWHMS algorithms, which includes (a) the AHRD algorithm and (b) the TB-AIC algorithm.

\subsubsection{Abnormal HR Detection (AHRD) Algorithm}

$\mathrm{HR}$ is the number of times a person's heart beats per minute (bpm). Normal HR varies from person to person according to a study by the Centers for Disease Control and Prevention (CDC), which indicated that the normal range of HR for adults is 60 to $100 \mathrm{bpm}$ (average resting heart rate). An abnormal HR of less than $60 \mathrm{bpm}$ is clinically defined as bradycardia, and an HR greater than $100 \mathrm{bpm}$ is defined as tachycardia [38,39]. In addition, they found that the target HR can be expressed as a percentage (generally between $50 \%$ and $85 \%$ ) for a maximum safe heart rate. The maximum rate is based on the age of the person, as subtracted from $220 \mathrm{bpm}$ [40]. Therefore, for a 50-year-old at a $50 \%$ exertion level, the target HR will be $85 \mathrm{bpm}((220-50) \times 50 \%)$. Whereas, at an exertion level of $85 \%$, the HR target would be $145 \mathrm{bpm}((220-50) \times 85 \%)$. Therefore, the target HR that a 50-year-old would want to aim for during exercise is 85 to $145 \mathrm{bpm}$ [41].

It is important to detect abnormal heartbeats because a damaged heart may cause deterioration of the patient within seconds and cause death (cessation of breathing and the pulse). In some cases, when the heartbeat dramatically increases to more than $145 \mathrm{bpm}$, this may be fatal to the patient. In addition, when an irregular HR occurs, the patient needs first-aid immediately [42]. Moreover, some factors, such as coronary heart disease, high blood pressure, endurance exercise, age, medication, caffeine, drugs, changes in the heart muscle after illness or injury, and other health conditions [43], can lead to an abnormal HR. However, a normal HR measurement depends on the individual and 
their age, body size, heart conditions, whether the person is sitting or moving, medication use, and even air temperature. Therefore, we set the HRth values (where HRth represents the threshold value of HR measurement) from 60 to $145 \mathrm{bpm}$ for the AWHMS when used outdoors during ADL. If the system detects a measured HR that differs abnormally from the selected HRth, the system waits $30 \mathrm{~s}$, then rechecks the HR measurement. If the detected HR remains abnormal relative to the threshold value according to the AHRD algorithm, the system will send a message to the MECC, including patient information (ID, HR abnormal, and geographic location). If the system detects that the measured HR was normal, the system will check for fall detection using the adopted TB-AIC algorithm, as shown in Figure 4a.

\subsubsection{Fall Detection Algorithm (TB-AIC)}

Some previous work has proposed fall detection devices that had low detection accuracies because they only adopted a threshold-based algorithm when they designed the device $[7,15,20]$. In this work, a hybridized algorithm is proposed that combines the acceleration-threshold-based fall detection and activity/inactivity detection internal functions of the ADXL345 sensor. The parameters utilized in the proposed TB-AIC algorithm, as shown in Figure 4b, include SMV, acceleration threshold ( $A$ th), time threshold ( $T$ th), activity counter, and inactivity counter. SMV represents the square root of the sum of three parameters of acceleration, $A_{x}, A_{y}$, and $A_{z}$. Since the direction of possible falls cannot be predicted, it is unsuitable to use just one axis. The advantage of using Equation (1) is that it is sensitive to all directions of the acceleration sensor [20].

When the body falls, SMV decreases to near zero gravity (g). The selected Ath value is then compared with the SMV value. $T_{t h}$ is the delay time used for checking whether the value of SMV remains low during that specific time period. Finally, two counters (activity and inactivity counters) are employed to determine how often the activity and inactivity of the patient are sensed. If the system detects that the value of SMV is less than the selected value of $A$ th and time $T$ th has passed, the system will check whether the body is active or inactive depending on the ACC sensor. If the system shows more inactivity than activity over a $20 \mathrm{~s}$ period, the TB-AIC algorithm will decide that a fall has been detected and send a message to the MECC, including the patient information (ID, fall detected, and geographic location). If the system detects that SMV has returned to a value greater than $A$ th before time $T$ th has passed, the TB-AIC algorithm will determine that no fall was detected, and the system will return to the normal operation of the AHRD algorithm.

$$
S M V=\sqrt{A_{x}^{2}+A_{y}^{2}+A_{z}^{2}}
$$

\section{Experiment Configuration}

The electrical circuit of the proposed AWHMS was designed and all electronic parts were assembled as shown in Figure 5a, then connected to one another on the printed circuit board (PCB) segment as in Figure $5 \mathrm{~b}$. The proposed system was enclosed in a shock-resistant plastic container that protects all components of the AWHMS from damage. The container is then placed inside a black rubber sleeve, both to make it easy to wear on the body and to block out light that would affect the HB sensor's operation. Four groups of volunteers were invited to this experiment. Each group consisted of six volunteers, which means 24 volunteers participated in this experiment. Groups one and two included young volunteers aged 23 to 25 and 26 to 29 years, respectively. Elderly volunteers who are taking medicine aged 61 to 63 and 64 to 66 years made up groups three and four, respectively. In the HB experiment, a total of 7200 samples of heart rate ( 6 volunteers $\times 300$ samples $\times 4$ groups) were recorded. For ACC classification, seven experiments were conducted, with one volunteer from each group participating in each experiment. A total of 224 samples were recorded for all experiments. Each experiment collected samples from four volunteers for two kinds of activity (i.e., normal activities and falls) and was repeated four times. 


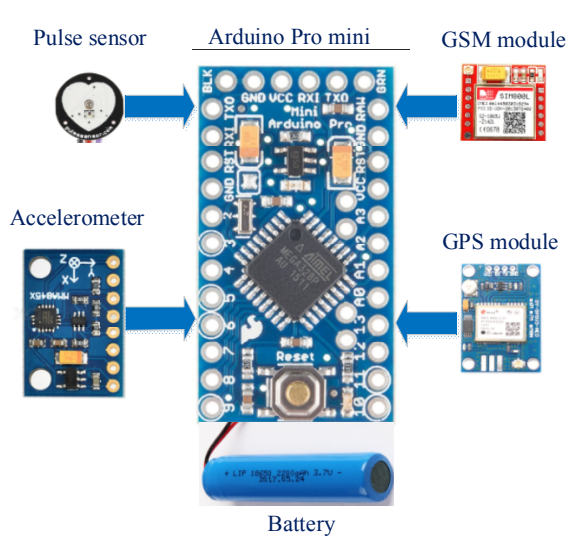

(a)

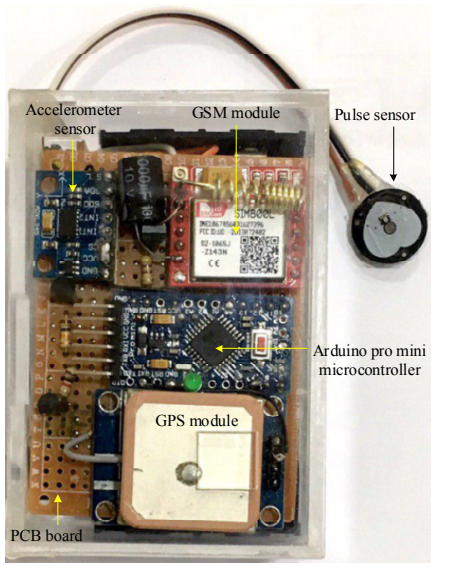

(b)

Figure 5. Proposed AWHMS device: (a) schematic diagram and (b) hardware.

The AWHMS was attached to the left upper arm of each volunteer. This location was very suitable for the HB sensor because the outer skin of the body in this location is very smooth and has high conductivity for the green LED. In addition, the adopted location increases the sensitivity of the ACC sensor to distinguish between normal activities and falls because it experiences less movement during ADL compared to positions used in other works, such as the wrist [6], belt [14], chest [8], ankles [10], leg [9], and waist [22].

The following subsections describe the experiments conducted to evaluate the HB and ACC sensors of the AWHMS separately:

\subsection{Heartbeat Sensor}

The HR measurements collected in real time by the HB sensor of the proposed AWHMS were compared with the HR measurements of the benchmark (BM) device to confirm and verify the accuracy of our prototype. A NONIN 7500fo device was adopted as the BM for comparison with the HR of the AWHMS. The A NONIN 7500fo was selected because it is a robust calibrated device, has a high HR measurement accuracy of $98 \%$ to $100 \%$ both with and without patient movement, it has an Spo2 accuracy from $70 \%$ to $100 \%$ and a pulse rate output range of 0 to $300 \mathrm{bpm}$ with a precision of \pm 5 digits during movement and \pm 3 digits for non-movement, and it has been approved by the Food and Drug Administration (FDA) [44]. In addition, the adopted BM has new technology not included with other consumer-ready devices called PureSAT technology. PureSAT technology uses intelligent pulse-by-pulse filtering to provide precise HR measurement. It was represented as a smart algorithm that automatically adjusts the measurement by averaging the HR every three seconds or faster [45].

In this experiment, all volunteers from the four groups were invited to record their HR. The experiment was conducted at PAR Hospital in Erbil, Iraq [46]. The examination room has a normal light environment with a temperature of $21^{\circ} \mathrm{C}$. In the experiment, shown in Figure 6, the HB sensors were fixed on the upper arm of the volunteers for the AWHMS and on the fingertip for the BM. Groups one and two (younger) were asked to jog inside the examination room of the hospital, whereas groups three and four (elderly) were asked to walk in the same location for three minutes while their HR was recorded. Parallax data acquisition software (PLX-DAQ, v2.10, Parallax Inc., Rocklin, CA, USA) [47] was used to record the HR measurements of the AWHMS and display them on a personal computer (PC) monitor. In addition, PLX-DAQ can be used to monitor HR measurements in an Excel file format in real time, as shown in Figure 7. Meanwhile, the HR measurements of the BM device were displayed in real time on the same PC through an RS232 cable. A total of 1200 samples (300 average samples from each group $\times 4$ groups) out of 7200 samples were used for data analysis. These samples were compared with 1200 samples of HR measurements collected by the BM device to evaluate the 
accuracy of the proposed AWHMS measurement. The results revealed that the HR measurements by the AWHMS differ slightly from the HR measurements of the BM device.

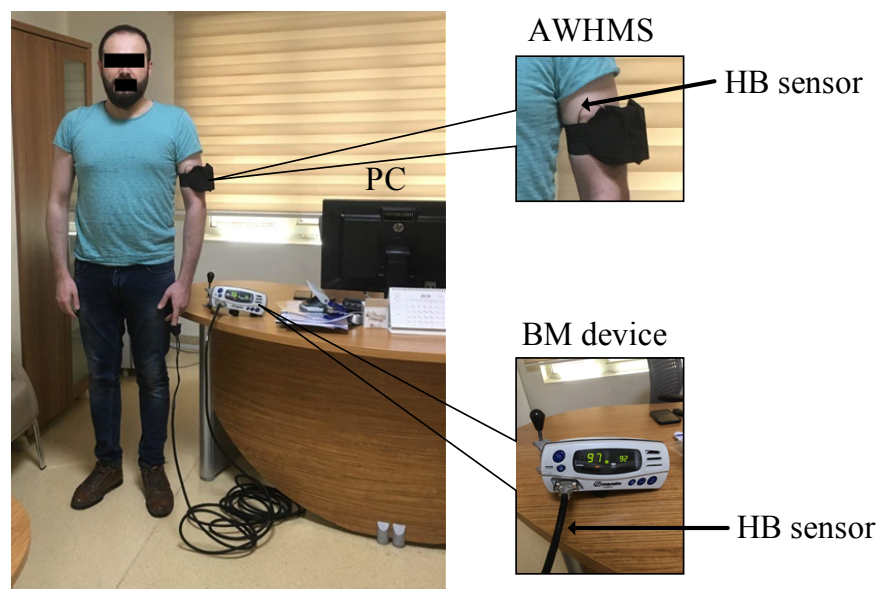

Figure 6. Connection the heartbeat sensors to the fingertip for the BM device and to the upper arm for the AWHMS.

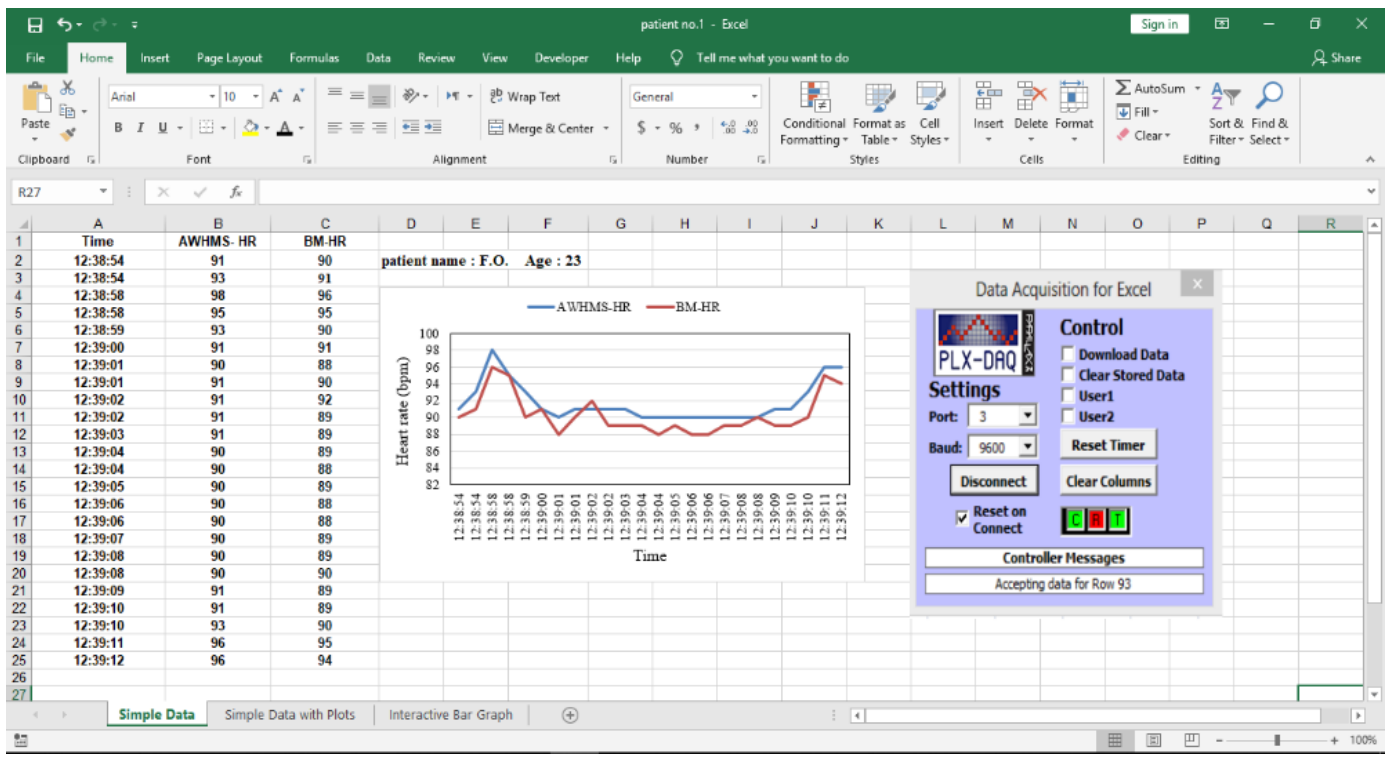

Figure 7. Data acquisition program based on PLX-DAQ for HR and BM measurement.

\subsection{ACC Sensor}

Regarding the ACC sensor performance experiment, the experiment was divided into seven sub-experiments. Each experiment consisted of two stages, as shown in Table 1. The first stage consisted of seven kinds of normal activities (e.g., walking, sitting, jumping). The second stage included seven kinds of falls (e.g., forward fall, fall to the right side, backward fall). The types of normal activities and falls were carefully chosen to focus on the most significant activities for both categories. In addition, they were used for testing the classification accuracy of the ACC sensor at distinguishing between falls and normal activities. 
Table 1. ACC classification experiments, with scenarios for seven types of ADLs and seven types of falls.

\begin{tabular}{ccc}
\hline Experiment & Stage 1 (ADL) & Stage 2 (Fall) \\
\hline 1 & walking & forward fall, landing on knees \\
2 & jumping & right fall, lying on the ground \\
3 & running & forward fall, lying on the ground \\
4 & lying on the bed & seated in bed, falling to the ground \\
5 & descending stairs & forward fall, lying on the leg \\
6 & running down the stairs & forward fall, lying on the hand \\
7 & rapidly sitting down on a chair & backward fall from a seated position on a chair \\
\hline
\end{tabular}

One volunteer from each group participated in each experiment. The AWHMS was attached to their upper arm to eliminate patient movement restrictions, as shown in Figure 8a-d. The experiments were carried out as follows. Each volunteer performed the normal activity pre-selected for the first stage of the first experiment for one minute. After the minute elapsed, the volunteer deliberately fell for one minute according to the fall position specified for the second stage of the first experiment. One minute after falling, the first experiment was complete. The volunteers applied these same steps to the remaining six experiments. In addition, an experiment operator manually recorded the results from the seven experiments, which include the performance of the ACC sensor in each stage and whether it classified the type of activity correctly. Each volunteer repeated the seven experiments four times to replicate the test results and to check the accuracy of the ACC sensor in distinguishing between falls and normal activities in order to assess the accuracy of the TB-AIC algorithm.

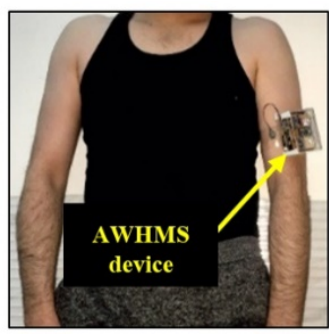

(a)

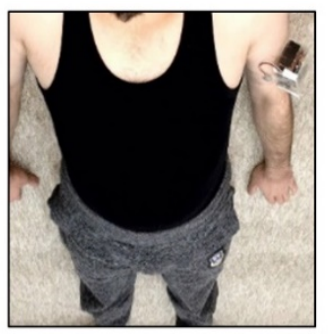

(b)

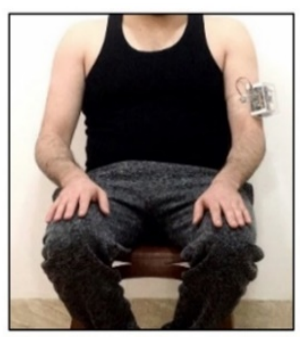

(c)

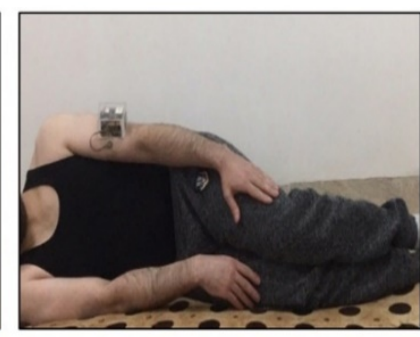

(d)

Figure 8. Experimental tests for (a) standing up rapidly from a seated position, (b) lying on the ground, (c) rapidly sitting down on a chair, and (d) lying on the side.

\section{Parameter Measurements}

This section will present the measurement results for the HB and ACC sensors.

\subsection{HR Measurements}

The experiment described in Section 4.1 was conducted to evaluate the HR measurement accuracy of the proposed AWHMS. Figure 9 illustrates the 300 average samples that were recorded for each group from the HB sensor experiment for both the AWHMS and the BM device to facilitate comparison and statistical analysis. Figure $9 a-d$ show the HR measurement during physical activities (jogging for groups one and two and walking for groups three and four). Statistical analysis was performed for the two datasets to validate the proposed AWHMS as described in Section 6.1. HB measurement based on the photoplethysmography (PPG) sensor essentially combines the optical HR sensor with noise cancellation and amplification circuitry making it easy and fast to acquire reliable heart pulse readings. However, PPG sensor measurement can be affected by the user's movements and the facial placement on the body [48], and thus the heart rate extraction from some locations, such as the thumb and wristband, will not be adequately accurate [40]. In this work, the upper arm location was selected due to its higher conductivity than the other locations for HR monitoring and to reduce the user's 
movement's effect. Therefore, in this work, the measurement accuracy based on the PPG sensor does not impact on decreasing the overall performance of the AWHMS.

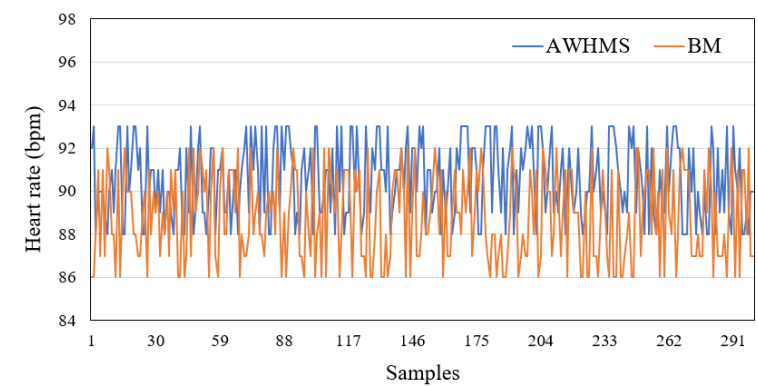

(a)

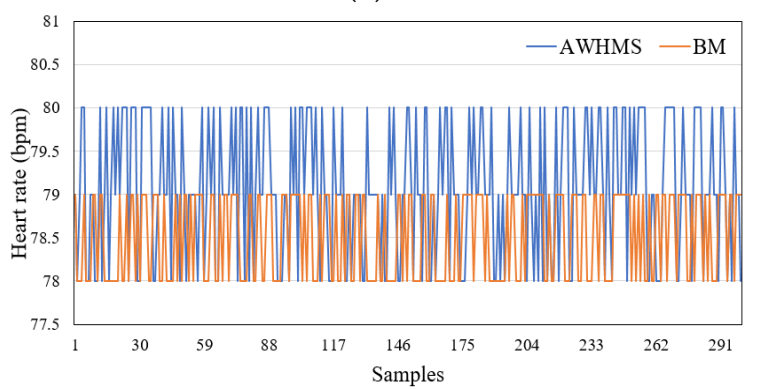

(c)

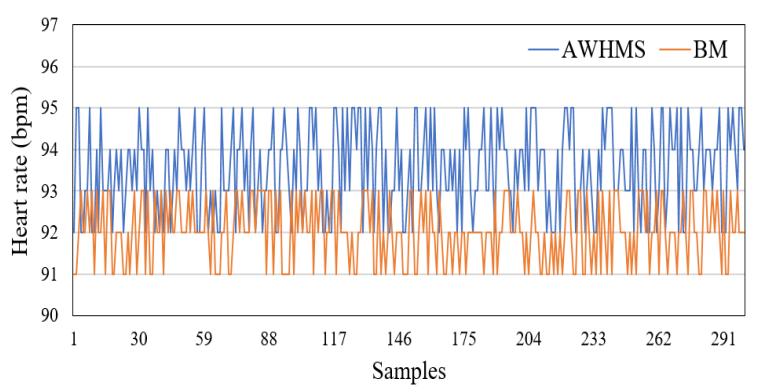

(b)

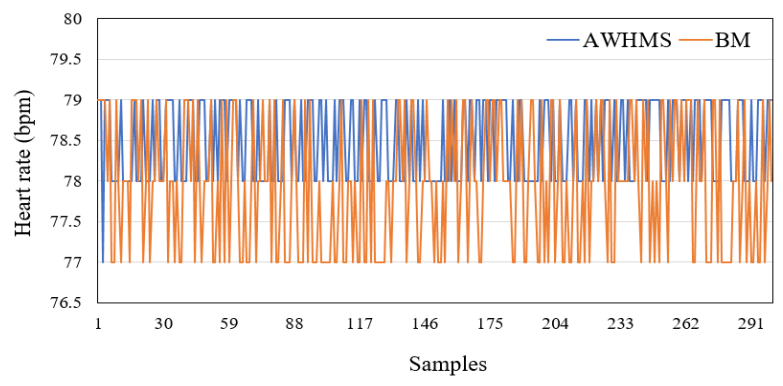

(d)

Figure 9. Plot of the data collected from the AWHMS and BM devices for volunteers (a) aged 23 to 25, (b) aged 26 to 29 , (c) aged 61 to 63 , and (d) aged 64 to 66 years.

\subsection{Accelerometer Measurement}

The performance of the AWHMS with respect to fall detection was evaluated for 14 activities. The total extracted data included 224 samples for all the volunteers, as shown below in Table 2 . The validation of the ACC sensor in terms of the accuracy of the classification between falls and normal activities is presented in Section 6.2. The ACC based on the ADXL345 sensor provides high measurement accuracy [49], where it supports measurement of inclination angle changes $<0.250$ o [50], it has high measurement resolution (13-bit up to $\pm 16 \mathrm{~g}$ ), and it was calibrated before starting measurements. Therefore, it does not have any impact on decreasing the overall measurement accuracy of the system.

Table 2. Patient activities, including seven types of fall and seven types of ADL.

\begin{tabular}{ccccc}
\hline Experiment & ADL (TN) & ADL (FP) & Fall (TP) & Fall (FN) \\
\hline 1 & 16 & 0 & 16 & 0 \\
2 & 16 & 0 & 16 & 0 \\
3 & 16 & 0 & 16 & 0 \\
4 & 16 & 0 & 15 & 1 \\
5 & 16 & 0 & 16 & 0 \\
6 & 15 & 1 & 16 & 0 \\
7 & 16 & 0 & 16 & 0 \\
Total & 111 & 1 & 111 & 1 \\
\hline
\end{tabular}

TP: the number of falls for which a fall was detected (true positives); TN: the number of ADLs for which no fall was detected (true negatives); FP: the number of ADLs for which a fall was detected (false positives); FN: the number of falls for which no fall was detected (false negative).

\section{Results and Discussions}

In this section, the heart rate measurements of the HB sensor are validated based on statistical analyses relative to the BM. The classification of the proposed TB-AIC algorithm was achieved relying 
on the ACC sensor. However, the performance of the TB-AIC was validated based on confusion metrics. In addition, the results of a test of data delivery based on a smartphone are presented.

\subsection{HR Measurement Validation}

The upper arm placement of the proposed device resulted in a more accurate measurement of HR. As shown in Figure 9, the average HR measurement during physical activities (jogging and walking) was $92.05 \mathrm{bpm}$ for younger volunteers (less than 30 years old) and $77.29 \mathrm{bpm}$ for elderly volunteers. The HR measurements of the elderly were less than $80 \mathrm{bpm}$ because they were taking medication that decreased the HR. This indicates that the HR threshold value (HRth) for the AHRD algorithm must be selected according to the age of the patient. Heart rate measurements were obtained using the AWHMS and BM devices, as seen in Figure 9. The figure reveals a slight difference between the systems. The measured data obtained by the proposed device was validated based on the data acquired by the BM device using statistical analyses as follows.

\subsubsection{Accuracy}

Measurement accuracy was identified as the difference between the HR measurements of the proposed device and the BM. The measurement accuracy can be computed based on Equation (2) [13]:

$$
\text { Accuracy }=\left(1-\frac{\text { estimatedHR }- \text { actual } H R \mid}{\text { actual } H R}\right) \times 100,
$$

where estimatedHR is the HR measured by the AWHMS and actualHR is the HR measured by the BM device.

As shown in Figure 9, the accuracy of the HR measurements was 98\%, 98.37\%, 99.28\%, and $99.29 \%$ for groups one through to four, respectively. These results indicate that a mean accuracy of $98.75 \%$ was obtained by the AWHMS. This means that the HR measurement accuracy of the AWHMS was compatible with the measurements of the BM device. This result encourages users to utilize the AWHMS for monitoring the HR of the patient, as it can give a trustworthy diagnosis of the patient status when the patient is a critical case.

\subsubsection{Error Test}

Mean absolute error (MAE), mean square error (MSE), root mean square error (RMSE), mean absolute percentage error (MAPE), and standard deviation (Std) were adopted as a statistical analysis to measure the difference between two continuous variables that have the same phenomena [5153]. The MAE has been employed in previous works to determine the difference between the HR measurements of proposed and BM systems. It is expressed in Equation (3) [22]:

$$
M A E=\frac{1}{n} \sum_{i=1}^{n} \text { lestimated } H R-\text { actualHR|, }
$$

where $n$ is the number of measurement samples.

Figure 10 shows the absolute error for each sample and the MAE of the AWHMS relative to the $\mathrm{BM}$ device. The error fluctuated between the range of 0 and7, with the highest error value of $7 \mathrm{bpm}$ in group 1. This is probably due to activity because we asked groups 1 and 2 to jog and groups 3 and 4 to walk. However, the jogging, running, and endurance exercises are susceptible to motion artifacts [54]. In addition, the HR has a high measurement accuracy of $98 \%$ to $100 \%$ both with and without patient movement as presented in Section 4.1, where both reasons lead to a variance between the HR measurements of the AWHMS and BM devices. Moreover, the error was significantly lower for the remaining samples (i.e., groups 3 and 4). 


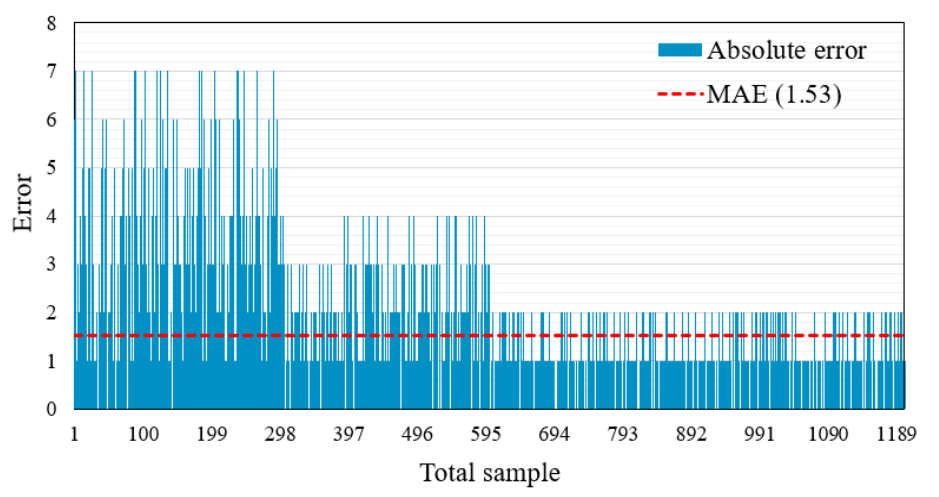

Figure 10. MAE measurements of the AWHMS.

The MAE of $1.53 \mathrm{bpm}$ indicates that the measurements of the two devices differ only slightly. In addition, the results of the MSE, MAPE, RMSE, and standard deviation for the HR measurements of the AWHMS and BM are presented in Table 3.

Table 3. Results of the error test.

\begin{tabular}{cccccc}
\hline Error & $\begin{array}{c}\text { Group 1 } \\
\text { (23-26 Years) }\end{array}$ & $\begin{array}{c}\text { Group 2 } \\
\text { (26-29) Years }\end{array}$ & $\begin{array}{c}\text { Group 3 } \\
\text { (61-63) Years }\end{array}$ & $\begin{array}{c}\text { Group 4 } \\
\text { (64-66) Years }\end{array}$ & Mean \\
\hline MAE & 2.81 & 1.63 & 0.83 & 0.86 & 1.53 \\
MSE & 3.174 & 3.97 & 1.15 & 1.26 & 2.38 \\
RMSE & 1.781 & 1.99 & 1.08 & 1.12 & 1.49 \\
MAPE & 3.08 & 1.73 & 1.04 & 1.09 & 1.74 \\
Std & 2.105 & 1.197 & 0.713 & 0.735 & 1.188 \\
\hline
\end{tabular}

\subsubsection{Correlation Coefficient Test}

The correlation coefficient $(\mathrm{R})$ is another statistical analysis that can reflect the correlation between two variables. Correlation coefficient values range between 1 and -1 according to the "Cauchy-Schwarz inequality" [55]. In this paper, it was used to estimate the correlation between AWHMS and BM measurements. The AWHMS measurements were plotted on the $x$-axis and the BM was plotted on the $y$-axis [52]. A linear fit line was plotted between the points to illustrate the correlation between AWHMS and BM, as shown in Figure 11. The correlation coefficient (R) was 0.9293, which indicates a close agreement between the measurements of the AWHMS and BM. A value of $R$ close to 1 denotes a strong positive linear correlation, $R$ close to 0 indicates no linear correlation, and $R$ close to -1 denotes a strong negative linear correlation [56]. It is defined as Equation (4) [57]:

$$
R=\frac{n\left(\sum x y\right)-\left(\sum x\right)\left(\sum y\right)}{\sqrt{\left[n \sum x^{2}-\left(\sum x\right)^{2}\right]\left[n \sum y^{2}-\left(\sum y\right)^{2}\right]}}
$$

where $x$ is the HR measurement data of the BM device and $y$ is the HR measurement data of the AWHMS. 


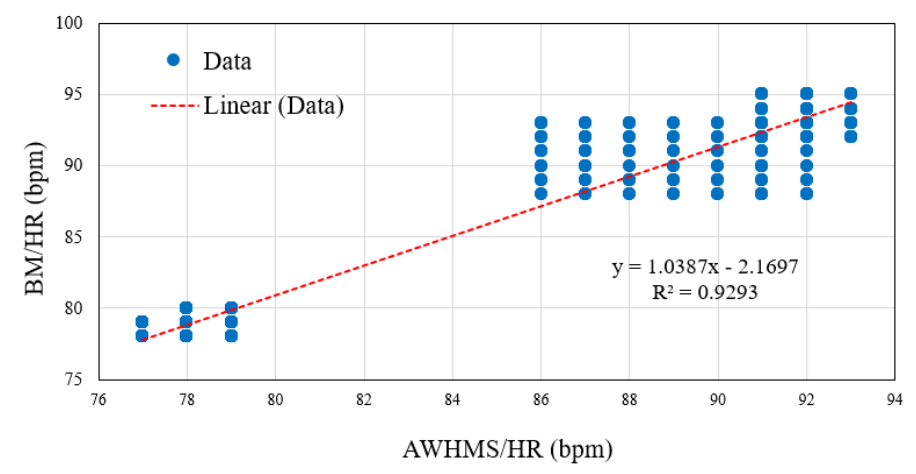

Figure 11. Correlation between AWHMS and BM HR data.

\subsubsection{Bland-Altman Plot}

The Bland-Altman plot, also called a difference plot, is a method of data plotting used in statistical analysis that can estimate the agreement between two different tests [58]. In addition, it is used to compare two clinical measurements that each produce some error in their measurement [59]. To evaluate this correlation formally, the relationship between the differences and the true value is identified and regression-based $95 \%$ limits of agreement should be provided. In this work, Bland-Altman was employed to test the similarity or differences between the measurements from the proposed AWHMS and the BM device [60].

Figure 12 shows a Bland-Altman plot of the variations in HR measurement for both devices ( $\mathrm{n}=1200$ samples). The results illustrate that four samples were outside of the limits of agreement (i.e., mean \pm 2 std) while 96 samples were inside the limits of agreement. This means that the AWHMS achieved $96 \%$ agreement with the BM within the $97.58 \%$ limits $(-4.75,2.56)$. The mean difference in the HR measurements between the AWHMS and BM devices was -1 , and the difference in standard deviation was 1.83. However, the width of the limits of agreement was 7.31 [2]. Moreover, the results show that the AWHMS achieves an excellent agreement with the BM device with significant matching between them [61].

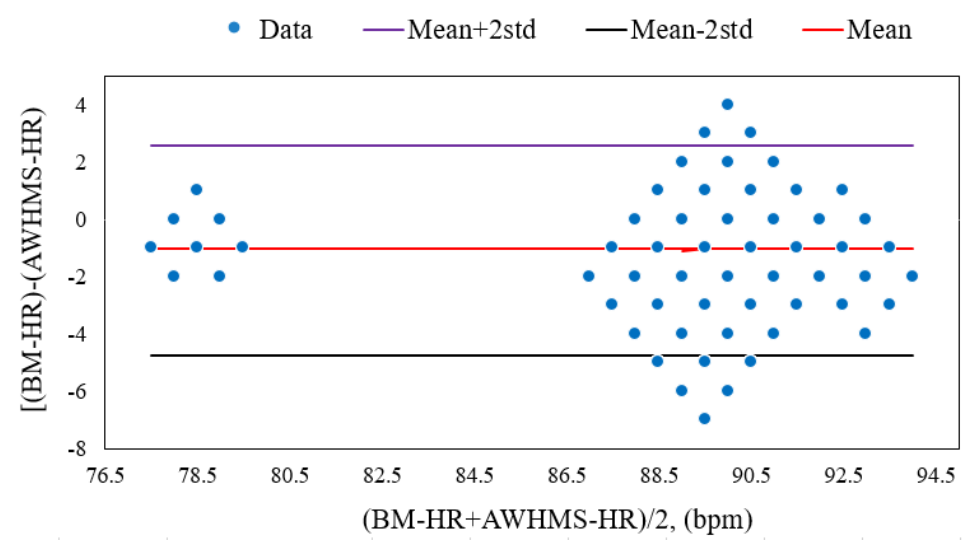

Figure 12. Bland-Altman plot of HR measurement. 


\subsection{Performance Validation of the Accelerometer Measurements}

To validate the accelerometer measurements, three performance metrics were adopted: Accuracy, sensitivity, and specificity. Accuracy is very important and can be used to explore the performance of the AWHMS at distinguishing between ADLs and falls [26]. It can be expressed based on the TN, TP, FN, and FP presented in Table 2 as in Equation (5) [16]:

$$
\operatorname{Accuracy}(\%)=\left(\frac{T N+T P}{T N+T P+F N+F P}\right) \times 100 .
$$

Sensitivity, sometimes called the "recall rate", is the ratio of correctly classified "positive statuses" to the entire set of positive statuses [62]. It is employed to quantify the ability of the proposed device to detect falling and is defined in Equation (6) [16]. Similarly, specificity, sometimes called the "true negative rate", is the ratio of correctly classified negative statuses to the entire set of negative statuses [63]. It is expressed in Equation (7) [16]:

$$
\begin{aligned}
& \operatorname{Sensitivity}(\%)=\left(\frac{T P}{T P+F N}\right) \times 100, \\
& \operatorname{Specificity}(\%)=\left(\frac{T N}{T N+F P}\right) \times 100 .
\end{aligned}
$$

Equations (5)-(7) were applied for all extracted samples, and the results are shown in Table 2. The accuracy, sensitivity, and specificity of the AWHMS for fall detection were $99.11 \%, 99.12 \%$, and $99.12 \%$, respectively [64]. These results indicate that the proposed device successfully discriminated between ADLs and FDs. One fall was not detected in experiment number four, as shown in Table 2, because (i) the distance between the bed and ground was small and (ii) the volunteer instinctively broke their fall with their arms, resulting in low acceleration. Therefore, the ADXL345 sensor could not reach a trigger threshold and fall detection did not occur.

\subsection{Test Data Delivery}

Figure 13a,b show an example of a message received from the proposed AWHMS on the smartphone at the MECC [18]. This experiment tested the delivery of 60 messages sent from the AWHMS to the smartphone from different cities in Iraq (i.e., Baghdad, Mosul, and Erbil), as shown in Table 4. The table indicates that all messages sent from the GSM module of the AWHMS to the MECC were received on the smartphone without information loss. This means that $100 \%$ information transmission was obtained in an urban area by the GSM module based on SIM800L. In comparison, previous work [19] achieved a $93.7 \%$ message delivery rate. This means that the GSM module adopted in this work is more reliable and can be used to send messages to the smartphone when critical cases occur. 


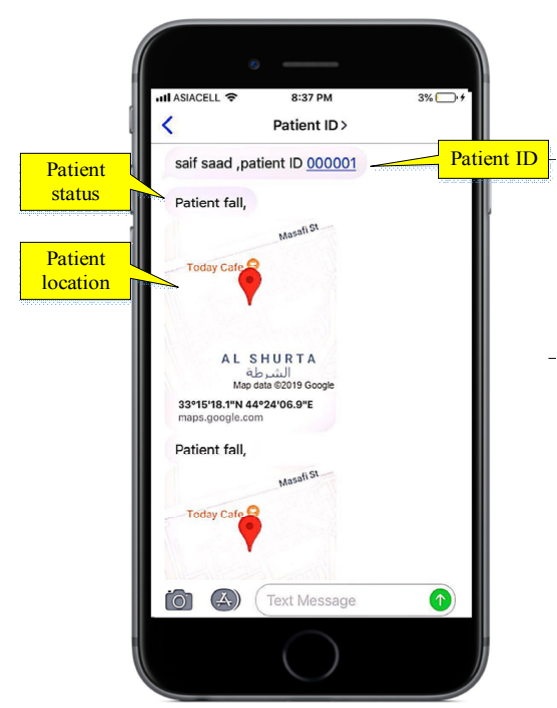

(a)

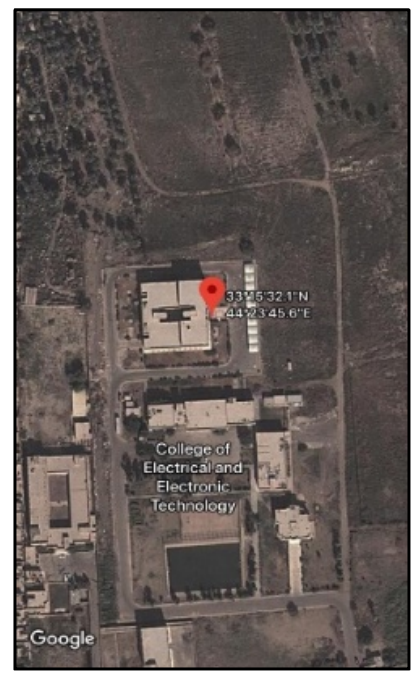

(b)

Figure 13. Messages sent to the smartphone at the MECC with (a) received message details and (b) location on the Google map.

Table 4. Results of test message delivery in different cities of Iraq.

\begin{tabular}{cccc}
\hline City & No. of Messages Sent & No. of Messages Received & Message Loss \\
\hline Baghdad & 10 & 10 & 0 \\
Mosul & 10 & 10 & 0 \\
Erbil & 40 & 40 & 0 \\
\hline
\end{tabular}

\section{Comparison with Previous Results}

The measurement accuracy, sensitivity, and specificity of the AWHMS using the TB-AIC algorithm were compared with the FD performances reported for previously published patient monitoring systems (Table 4) to evaluate the proposed system. Several reliable studies that were similar to the present work in terms of monitoring patient vital signs, such as body temperature, blood pressure, heart rate, fall detection, breathing rate, $\mathrm{SpO} 2$, patient's activities, etc., were compared with the AWHMS.

These works used different wireless communication methods, such as ZigBee, GSM, nRF24L01, and Bluetooth, to communicate vital sign data from patients to a monitoring device. In addition, sensor location is highlighted to explore the best location on the patient's body. The proposed AWHMS relying on the TB-AIC algorithm outperformed the other studies in terms of accuracy, sensitivity, and specificity; the AWHMS achieved 99.11\%, 99.12\%, and 99.12\%, respectively, as seen in Table 5 . 
Table 5. Comparison of accuracy for FD and HR measurement with related works.

\begin{tabular}{|c|c|c|c|c|c|c|c|c|}
\hline \multirow{2}{*}{ Ref./Year } & \multirow{2}{*}{$\begin{array}{l}\text { Fall Detection } \\
\text { Algorithm }\end{array}$} & \multirow{2}{*}{$\begin{array}{l}\text { Wireless } \\
\text { Technology }\end{array}$} & \multirow{2}{*}{ Sensor Type } & \multirow{2}{*}{$\begin{array}{c}\text { Sensor } \\
\text { Location }\end{array}$} & \multicolumn{2}{|c|}{ Accuracy (\%) } & \multirow{2}{*}{$\begin{array}{c}\text { Sensitivity (\%) } \\
\text { FD }\end{array}$} & \multirow{2}{*}{$\begin{array}{c}\text { Specificity (\%) } \\
\text { FD }\end{array}$} \\
\hline & & & & & FD & Measurement & & \\
\hline$[9] / 2013$ & Entropy, HMM & Bluetooth & SEMG, ACC & Leg & $\begin{array}{l}>95 \text { (Entropy) and }>95 \\
(\text { HMM) }\end{array}$ & N/A & 95.33 & 97.66 \\
\hline$[6] / 2014$ & CHMM & Zigbee & ACC, Spo2, HB & $\begin{array}{l}\text { Wrist, Chest } \\
\text { Ankles }\end{array}$ & 94.8 (СHMM) & $\begin{array}{l}88.75 \text { (ECG) } 93.75 \\
(\text { Spo2) }\end{array}$ & N/A & N/A \\
\hline$[7] / 2014$ & Threshold-based & Bluetooth & $\begin{array}{l}\text { ACC, HB, Temp., } \\
\text { Hum. }\end{array}$ & Chest & 97 (ACC) & $\begin{array}{l}\text { 99.5(Temp.), } 89.9 \\
\text { (Hum.), } 95 \text { (HR) }\end{array}$ & N/A & N/A \\
\hline$[12] / 2014$ & State machine & Smartphone & $\mathrm{ACC}$ & Pocket Belt & $\begin{array}{l}97.5 \text { (FD-Pocket), } 97.6 \\
\text { (FD-Belt) }\end{array}$ & N/A & $\begin{array}{l}96.6 \text { (FD-Pocket) } \\
97 \text { (FDBelt) }\end{array}$ & $\begin{array}{l}98.6 \text { (FD-Pocket) } \\
98.4 \text { (FD-Belt) }\end{array}$ \\
\hline$[15] / 2014$ & Threshold-based & Zigbee & ACC, $\mathrm{HB}$ & $\mathrm{N} / \mathrm{A}$ & 97.5 (classification) & $\mathrm{N} / \mathrm{A}$ & 96.8 & 98.1 \\
\hline [20]/2014 & Threshold-based & Zigbee & ACC Gyroscopes & Wrist & $\mathrm{N} / \mathrm{A}$ & $\mathrm{N} / \mathrm{A}$ & 95 & 96.7 \\
\hline$[8] / 2015$ & N/A & Bluetooth & $\begin{array}{l}\text { HB, Temp. Blood } \\
\text { pressure }\end{array}$ & Chest & N/A & $\begin{array}{l}>90 \text { (all vital } \\
\text { measurements) }\end{array}$ & N/A & N/A \\
\hline$[14] / 2015$ & Threshold-based & GSM & ACC & Belt & $\mathrm{N} / \mathrm{A}$ & N/A & 97.1 & 98.3 \\
\hline$[63] / 2015$ & $\begin{array}{l}\text { Threshold-based + } \\
\text { HMM }\end{array}$ & Zigbee & ACC & N/A & $96.25(\mathrm{FD})$ & $\mathrm{N} / \mathrm{A}$ & 98.75 & 94.38 \\
\hline$[5] / 2017$ & Non-linear SVM & Bluetooth & Smart textiles & Belt & $98(\mathrm{FD})$ & N/A & 97.5 & 98.5 \\
\hline$[10] / 2017$ & Log-Sum distance & Bluetooth & ACC & Ankles & 99 (Log-Sum distance) & N/A & N/A & N/A \\
\hline$[13] / 2017$ & N/A & Bluetooth & Heartbeat & Chest & N/A & 92.79(HR) & N/A & N/A \\
\hline$[21] / 2018$ & N/A & N/A & Heart rate & Chest & N/A & $>90$ (HR) & N/A & N/A \\
\hline$[22] / 2018$ & ANN & Zigbee & ACC, Tilt HB & Waist & $\begin{array}{l}\text { 92.5 (FD-NLOS } \\
\text { environment) }\end{array}$ & & N/A & N/A \\
\hline$[51] / 2018$ & N/A & Zigbee & HB, Spo2, Temp. & Wrist & N/A & $\begin{array}{l}98.5 \text { (HR), } 98.6 \text { (Spo2), } \\
99.9 \text { (Temp.) }\end{array}$ & N/A & N/A \\
\hline$[61] / 2018$ & N/A & nRF24L01+ & $\begin{array}{l}\text { HB, Spo2 ECG, } \\
\text { Breathing }\end{array}$ & N/A & N/A & $\begin{array}{l}\text { Good (ECG and } \\
\text { breathing), Excellent } \\
\text { (SPO2 and HR) }\end{array}$ & N/A & N/A \\
\hline$[62] / 2018$ & Threshold-based & Zigbee & ACC Barometer & Neck & N/A & N/A & 91 & N/A \\
\hline$[64] / 2018$ & TBM, TBM-MD & N/A & $\begin{array}{l}\text { ACC Gyroscopes } \\
\text { Magnetometer }\end{array}$ & Wrist & $\begin{array}{l}91.1 \text { (TBM) } 99 \\
\text { (TBM-MD) }\end{array}$ & N/A & $\begin{array}{l}95.8 \text { (TBM) } 100 \\
\text { (TBM-MD) }\end{array}$ & $\begin{array}{l}86.5 \text { (TBM) } 97.9 \\
\text { (TBM-MD) }\end{array}$ \\
\hline $\begin{array}{l}\text { Current } \\
\text { work }\end{array}$ & TB-AIC & GSM & $\mathrm{ACC}, \mathrm{HB}$ & Upper Arm & 99.11 (TB-AIC) & 98.75 (HR) & 99.12 (TB-AIC) & 99.12 (TB-AIC) \\
\hline
\end{tabular}

FD-NLOS: fall detection for non-line of sight; Hum.: Humidity; Temp.: Temperature; TBM: Threshold-based method; TBM-MD: Threshold based method with Madgwick's decomposition. 


\section{Conclusions}

A small AWHMS was designed and implemented for patient HR and FD monitoring based on GSM wireless technology. The proposed device consists of two sensors (heartbeat and accelerometer). They were used to collect heart rate and acceleration measurements for the patient, which were sent to a microcontroller for processing, monitoring, and to determine when to send an alert for a critical case. In addition, a GPS module was included to acquire the location of the patient and a GSM module to send a text message to a MECC. As part of this system, the MECC has a smartphone for receiving messages from the AWHMS; these messages include all information required to help the patient when an emergency occurs.

In this study, 24 volunteers (12 young and 12 elderly) were invited to evaluate the performance of the HB and ACC sensors. In the HB experiment, the AWHMS was attached to the left upper arm of the patient because this part of the body tends to experience less motion during daily activities. In addition, the outer skin of the upper arm is soft, clean, and has good conductivity for the heartbeat sensor. A consumer-ready device was adopted as the BM to confirm the HR measurement of the proposed AWHMS and the monitor was connected to the fingertip of the volunteers. A total of 7200 samples of the HR were recorded from each AWHMS and BM system. Regarding the ACC classification, seven experiments were conducted, with one volunteer from each group participating in each experiment. The experiment collected samples from four volunteers for two kinds of activity (i.e., normal activities and falls) and was repeated four times. The total number of samples recorded from the ACC experiment was 224.

The proposed device was validated in terms of HR measurement by using statistical analyses (e.g., absolute error, MAE, Bland-Altman test, standard deviation, and correlation coefficient test). The results of the statistical analyses provide a powerful indication of the validity of the proposed device. In addition, the proposed device has excellent accuracy results for FD because it adopts a hybridized algorithm that uses the internal functions of the selected ACC sensor to determine whether the body is falling or not. Therefore, this device achieves excellent effectiveness in the measurement of biomedical data compared to similar proposed devices. This application will certainly be useful for future research in the field of human health care and the provision of first aid. Future work will focus on further improving the measurement accuracy of the AWHMS. Future work can also build on the fact that the patient's longitude and latitude can be obtained from the GPS for the purpose of sending a first aid kit to the patient via a drone.

Author Contributions: Conceptualization, S.S.F. and S.K.G.; methodology, S.S.F. and S.K.G.; software, S.S.F.; validation, S.S.F. and S.K.G.; formal analysis, S.S.F.; resources, S.S.F. and S.K.G.; data curation, S.S.F. and S.K.G.; writing-original draft preparation, S.S.F.; writing-review and editing, S.K.G.; visualization, S.S.F.; supervision, S.K.G.

Funding: This research received no external funding.

Acknowledgments: The authors would like to thank the Department of Medical Techniques Engineering, Electrical Engineering Technical College, Middle Technical University for their support of this work. Also, the authors thank the PAR hospital where the experiment was conducted.

Conflicts of Interest: The authors declare no conflict of interest.

\section{Abbreviations}

This section contains all the abbreviations mentioned in this study as shown below:

ACC Accelerometer

ADL Activities of daily living

AHRD Abnormal heart rate detection

Ath Acceleration threshold

AWHMS Autonomous wireless health monitoring system

BM Benchmark

CDC Centers for Disease Control and Prevention 


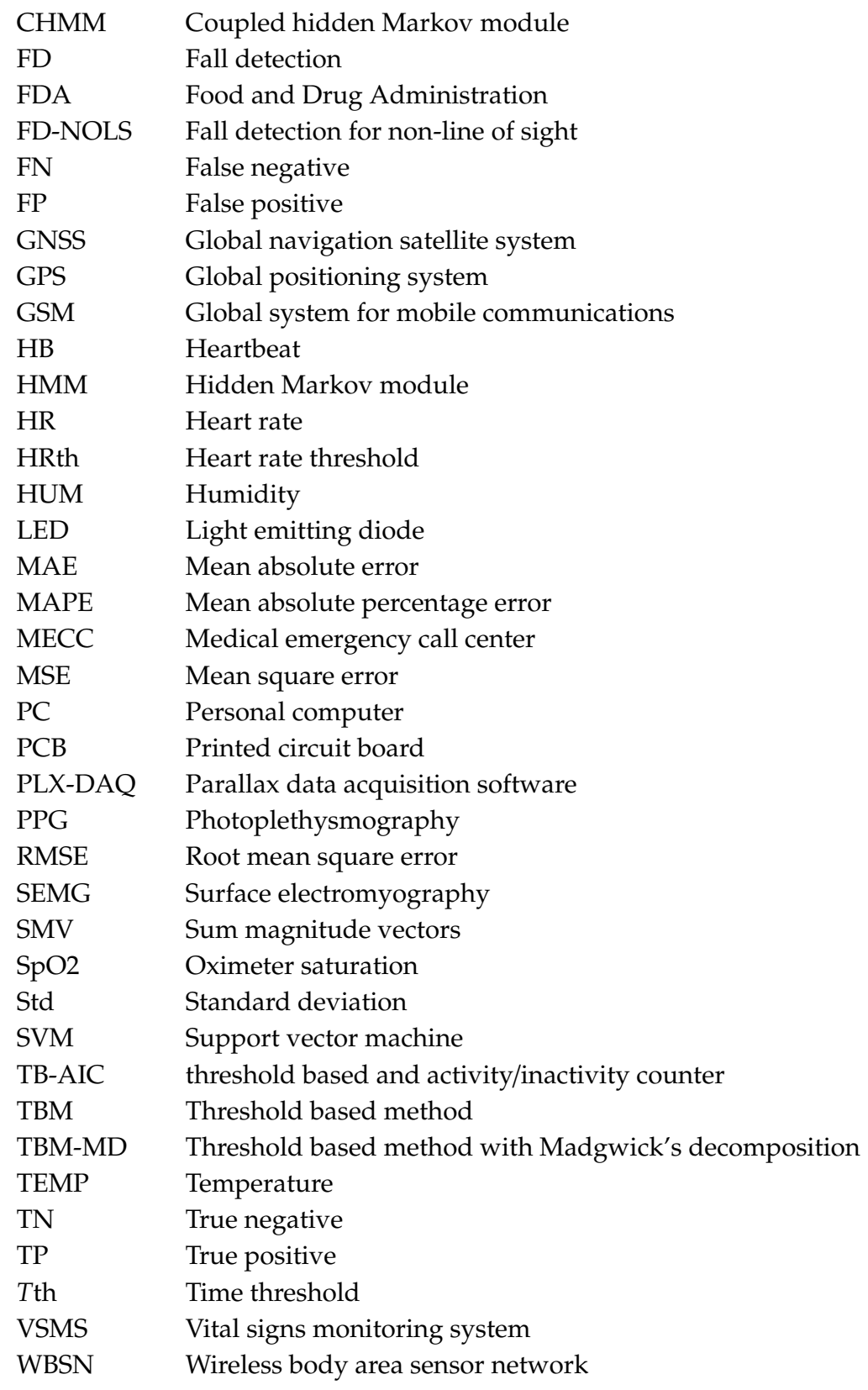

\section{References}

1. Harbouche, A.; Djedi, N.; Erradi, M.; Ben-Othman, J.; Kobbane, A. Model driven flexible design of a wireless body sensor network for health monitoring. Comput. Netw. 2017, 129, 548-571. [CrossRef]

2. Fajkus, M.; Nedoma, J.; Martinek, R.; Vasinek, V.; Nazeran, H.; Siska, P. A non-invasive multichannel hybrid fiber-optic sensor system for vital sign monitoring. Sensors 2017, 17, 111. [CrossRef] [PubMed]

3. Amin, R.; Islam, S.H.; Biswas, G.P.; Khan, M.K.; Kumar, N. A robust and anonymous patient monitoring system using wireless medical sensor networks. Futur. Gener. Comput. Syst. 2018, 80, 483-495. [CrossRef]

4. Fouad, H.; Farouk, H. Heart rate sensor node analysis for designing internet of things telemedicine embedded system. Cogent Eng. 2017, 4, 1-12. [CrossRef]

5. Mezghani, N.; Ouakrim, Y.; Islam, M.R.; Yared, R.; Abdulrazak, B. Context aware adaptable approach for fall detection bases on smart textile. In Proceedings of the 2017 IEEE EMBS International Conference on Biomedical \& Health Informatics (BHI), Orlando, FL, USA, 16-19 February 2017.

6. Wang, Z.; Zhao, C.; Qiu, S. A system of human vital signs monitoring and activity recognition based on body sensor network. Sens. Rev. 2014, 34, 42-50. [CrossRef] 
7. Kantoch, E.; Augustyniak, P.; Markiewicz, M.; Prusak, D. Monitoring activities of daily living based on wearable wireless body sensor network. In Proceedings of the 2014 36th Annual International Conference of the IEEE Engineering in Medicine and Biology Society, Chicago, IL, USA, 26-30 August 2014.

8. Kakria, P.; Tripathi, N.K.; Kitipawang, P. A Real-Time Health Monitoring System for Remote Cardiac Patients Using Smartphone and Wearable Sensors. Int. J. Telemed. Appl. 2015, 2015, 373474. [CrossRef] [PubMed]

9. Cheng, J.; Chen, X.; Shen, M. A framework for daily activity monitoring and fall detection based on surface electromyography and accelerometer signals. IEEE J. Biomed. Health. Inform. 2013, 17, 38-45. [CrossRef] [PubMed]

10. Sikder, F.; Sarkar, D. Log-sum distance measures and its application to human-activity monitoring and recognition using data from motion sensors. IEEE Sens. J. 2017, 17, 4520-4533. [CrossRef]

11. Gia, T.N.; Tcarenko, I.; Sarker, V.K.; Rahmani, A.M.; Westerlund, T.; Liljeberg, P.; Tenhunen, H. IoT-based fall detection system with energy efficient sensor nodes. In Proceedings of the IEEE Nordic Circuits and Systems (Norcas'16), Copenhagen, Denmark, 1-2 November 2016.

12. Aguiar, B.; Rocha, T.; Silva, J.; Sousa, I. Accelerometer-based fall detection for smartphones. In Proceedings of the 2014 IEEE International Symposium on Medical Measurements and Applications (MeMeA), Lisboa, Portugal, 11-12 June 2014.

13. Depari, A.; Flammini, A.; Bellagente, P.; Sisinni, E.; Crema, C.; Vezzoli, A. Virtual Respiratory Rate Sensors: An Example of a Smartphone-Based Integrated and Multiparametric mHealth Gateway. IEEE Trans. Instrum. Meas. 2017, 66, 2456-2463.

14. Wu, F.; Zhao, H.; Zhao, Y.; Zhong, H. Development of a Wearable-Sensor-Based Fall Detection System. Int. J. Telemed. Appl. 2015, 2015, 576364. [CrossRef]

15. Wang, J.; Zhang, Z.; Li, B.; Lee, S.; Sherratt, R. An enhanced fall detection system for elderly person monitoring using consumer home networks. IEEE Trans. Consum. Electron. 2014, 60, 23-29. [CrossRef]

16. Delahoz, Y.S.; Labrador, M.A. Survey on fall detection and fall prevention using wearable and external sensors. Sensors 2014, 14, 19806-19842. [CrossRef] [PubMed]

17. Panicker, N.V.; Kumar, A.S. Design of a telemonitoring system for detecting falls of the elderly. In Proceedings of the 2015 International Conference on Green Computing and Internet of Things (ICGCIoT), Noida, India, 14 January 2016.

18. Aziz, K.; Tarapiah, S.; Ismail, S.H.; Atalla, S. Smart real-time healthcare monitoring and tracking system using GSM/GPS technologies. In Proceedings of the 2016 3rd MEC International Conference on Big Data and Smart City, Muscat, Oman, 15-16 March 2016.

19. Siregar, B.; Andayani, U.; Bahri, R.P.; Fahmi, F. Real-time monitoring system for elderly people in detecting falling movement using accelerometer and gyroscope. J. Phys. Conf. Ser. 2018, 978, 012110. [CrossRef]

20. Hsieh, S.L.; Chen, C.C.; Wu, S.H.; Yue, T.W. A wrist-worn fall detection system using accelerometers and gyroscopes. In Proceedings of the 11th IEEE International Conference on Networking, Sensing and Control, Miami, FL, USA, 7-9 April 2014.

21. Nosrati, M.; Tavassolian, N. High-Accuracy Heart Rate Variability Monitoring Using Doppler Radar Based on Gaussian Pulse Train Modeling and FTPR Algorithm. IEEE Trans. Microw. Theory Tech. 2018, 66, 556-567. [CrossRef]

22. Gharghan, S.K.; Mohammed, S.L.; Al-Naji, A.; Abu-AlShaeer, M.J.; Jawad, H.M.; Jawad, A.M.; Chahl, J. Accurate fall detection and localization for elderly people based on neural network and energy-efficient wireless sensor network. Energies 2018, 11, 2866. [CrossRef]

23. Lithium Polymer Battery Safety Data Sheet. Available online: https://system.na3.netsuite.com (accessed on 5 March 2019).

24. Pittet, V.; Burnand, B.; Yersin, B.; Carron, P.N. Trends of pre-hospital emergency medical services activity over 10 years: A population-based registry analysis. BMC Health Serv. Res. 2014, 14, 380. [CrossRef] [PubMed]

25. Wang, D.; Liu, Y.; Jiang, M. Review on emergency medical response against terrorist attack. Mil. Med. Res. 2014, 1, 9. [CrossRef] [PubMed]

26. Pernini, L.; Palma, L.; Pierleoni, P.; Valenti, S.; Pellegrini, M.; Belli, A. A High Reliability Wearable Device for Elderly Fall Detection. IEEE Sens. J. 2015, 15, 4544-4553.

27. Rihana, S.; Mondalak, J. Wearable fall detection system. In Proceedings of the 2016 3rd Middle East Conference on Biomedical Engineering, Beirut, Lebanon, 6-7 October 2016.

28. Ning, J. Detecting Human Falls with a 3-Axis Digital Accelerometer. Analog. Dialogue 2009, 43, 3. 
29. Malmivuo, P.; Malmivuo, J.; Plonsey, R. Bioelectromagnetism: Principles and Applications of Bioelectric and Biomagnetic Fields; Oxford University Press: New York, NY, USA, 1995; pp. 588-595. Available online: http://www.bem.fi/book/book.pdf (accessed on 4 March 2019).

30. Butca, C.G.; Suciu, G.; Ochian, A.; Fratu, O.; Halunga, S. Wearable sensors and cloud platform for monitoring environmental parameters in e-health applications. In Proceedings of the 2014 11th International Symposium on Electronics and Telecommunications, Timisoara, Romania, 14-15 November 2014.

31. Arduino. Available online: https://cdn.sparkfun.com/datasheets/Dev/Arduino/Boards/ProMini16MHzv1.pdf (accessed on 4 March 2019).

32. Ali, A.S.; Zanzinger, Z.; Debose, D.; Stephens, B. Open Source Building Science Sensors (OSBSS): A low-cost Arduino-based platform for long-term indoor environmental data collection. Build. Environ. 2016, 100, 114-126. [CrossRef]

33. Sim8001. Available online: https://img.filipeflop.com/files/download/Datasheet_SIM800L.pdf (accessed on 4 March 2019).

34. Leu, F.; Ko, C.; You, I.; Choo, K.K.R.; Ho, C.L. A smartphone-based wearable sensors for monitoring real-time physiological data. Comput. Electr. Eng. 2018, 65, 376-392. [CrossRef]

35. U-blox NEO-M8: U-blox Concurrent GNSS Modules-Data Sheet. Available online: https://www.u-blox. com/sites/default/files/NEO-M8-FW3_DataSheet_\%28UBX-15031086\%29.pdf (accessed on 8 March 2019).

36. Grigulo, J.; Becker, L.B. Experimenting Sensor Nodes Localization in WSN with UAV Acting as Mobile Agent. In Proceedings of the 2018 IEEE 23rd International Conference on Emerging Technologies and Factory Automation, Turin, Italy, 4-7 September 2018.

37. Skoglund, M.; Petig, T.; Vedder, B.; Eriksson, H.; Schiller, E.M. Static and dynamic performance evaluation of low-cost RTK GPS receivers. In Proceedings of the 2016 IEEE Intelligent Vehicles Symposium, Gothenburg, Sweden, 19-22 June 2016.

38. Ostchega, Y.; Porter, K.S.; Hughes, J.; Dillon, C.F.; Nwankwo, T. Resting pulse rate reference data for children, adolescents, and adults: United States, 1999-2008. Natl. Health Stat. Rep. 2011, 41, 1-16.

39. Pirbhulal, S.; Zhang, H.; Wu, W.; Mukhopadhyay, S.C.; Zhang, Y.T. Heartbeats Based Biometric Random Binary Sequences Generation to Secure Wireless Body Sensor Networks. IEEE Trans. Biomed. Eng. 2018, 65, 2751-2759. [CrossRef] [PubMed]

40. Hwang, S.; Seo, J.O.; Jebelli, H.; Lee, S.H. Feasibility analysis of heart rate monitoring of construction workers using a photoplethysmography (PPG) sensor embedded in a wristband-type activity tracker. Autom. Constr. 2016, 71, 372-381. [CrossRef]

41. Physical Activity Basics, Physical Activity, CDC. Available online: https://www.cdc.gov/physicalactivity/ basics/index.htm (accessed on 7 June 2019).

42. Ventricular Fibrillation: Treatment, Causes, and Symptoms. Available online: https://www.medicalnewstoday. com (accessed on 6 July 2019).

43. Abnormal Heart Rhythms: Causes, Symptoms and Diagnosis. Available online: https://www.healthline.com (accessed on 4 July 2019).

44. Model 7500 | Nonin. Available online: https://www.nonin.com/support/7500/ (accessed on 4 March 2019).

45. Model 7500 Series. Available online: https:/www.nonin.com/wp-content/uploads/2018/09/Spec-SheetModel-7500.pdf (accessed on 4 March 2019).

46. PAR Hospital Erbil. Available online: http://parhospital.org/ (accessed on 7 March 2019).

47. El Ghzizal, A.; Motahhir, S.; Derouich, A.; El Hammoumi, A.; Chalh, A. Low-cost virtual instrumentation of PV panel characteristics using Excel and Arduino in comparison with traditional instrumentation. Renew. Wind Water Sol. 2018, 5, 3.

48. Smaldone, C.J.; Chabot, E.; Sun, Y. Impact of Placement of Facial PPG Sensor on Pulse-Rate Monitoring Accuracy. In Proceedings of the 43rd Annual Northeast Bioengineering Conference, Newark, NJ, USA, 2 March 2017.

49. Saha, A.; Das, S.; Suresh, M.; Raj Kiran, V.; Dey, N. FPGA based self-vibration compensated two dimensional non-contact vibration measurement using 2D position sensitive detector with remote monitoring. Meas. J. Int. Meas. Confed. 2017, 111, 271-278. [CrossRef]

50. Yuan, X.; Li, J.N.; Fang, Z. Hardware Design of Fall Detection System Based on ADXL345 Sensor. In Proceedings of the 2015 8th International Conference on Intelligent Computation Technology and Automation, Nanchang, China, 14-15 June 2015. 
51. Fakhri, A.B.; Gharghan, S.K.; Mohammed, S.L. Statistical validation of patient vital signs based on energy-efficient wireless sensor network monitoring system. ARPN J. Eng. App. Sci. 2018, 13, 8258-8270.

52. Lu, G.; Yang, F. Limitations of oximetry to measure heart rate variability measures. Cardiovasc. Eng. 2009, 9, 119-125. [CrossRef]

53. Lu, G.; Yang, F.; Taylor, J.A.; Stein, J.F. A comparison of photoplethysmography and ECG recording to analyse heart rate variability in healthy subjects. J. Med. Eng. Technol. 2009, 33, 634-641. [CrossRef]

54. Schäfer, A.; Vagedes, J. How accurate is pulse rate variability as an estimate of heart rate variability? A review on studies comparing photoplethysmographic technology with an electrocardiogram. Int. J. Cardiol. 2013, 166, 15-29. [CrossRef]

55. Zhang, H.; Safaei, F.; Tran, L.C. A Novel Cooperation-Based Network Coding Scheme for Walking Scenarios in WBANs. Wirel. Commun. Mob. Comput. 2017, 2017, 6267579. [CrossRef]

56. Theodorsson, E.; Dahlqvist, S.; Attvall, S.; Sandgren, U.; Skrtic, S.; Lind, M.; Pivodic, A.; Ólafsdóttir, A.F. A Clinical Trial of the Accuracy and Treatment Experience of the Flash Glucose Monitor FreeStyle Libre in Adults with Type 1 Diabetes. Diabetes Technol. Ther. 2017, 19, 164-172.

57. Social Research Methods Knowledge Base-Correlation. Available online: https://socialresearchmethods. net/kb/statcorr.php (accessed on 30 March 2019).

58. Valipour, A.; Abbasi-kesbi, R. A Heartbeat and Respiration Rate Sensor Based on a Phonocardiogram for Healthcare Applications. In Proceedings of the 2017 Iranian Conference on Electrical Engineering, Tehran, Iran, 2-4 May 2017.

59. Neumayer, C.; Klinger, M.; Huk, I.; Nanobachvili, J.; Polanczyk, A. Artificial Circulatory Model for Analysis of Human and Artificial Vessels. Appl. Sci. 2018, 8, 1017.

60. Zhang, Z.; Pi, Z.; Liu, B. TROIKA: A general framework for heart rate monitoring using wrist-type photoplethysmographic signals during intensive physical exercise. IEEE Trans. Biomed. Eng. 2015, 62, 522-531. [CrossRef]

61. Baba, E.; Jilbab, A.; Hammouch, A. A health remote monitoring application based on wireless body area networks. In Proceedings of the 2018 International Conference on Intelligent Systems and Computer Vision, Fez, Morocco, 2-4 April 2018.

62. Wang, C.; Lu, W.; Redmond, S.J.; Stevens, M.C.; Lord, S.R.; Lovell, N.H. A Low-Power Fall Detector Balancing Sensitivity and False Alarm Rate. IEEE J. Biomed. Health. Inform. 2018, 22, 1929-1937. [CrossRef] [PubMed]

63. Lim, D.; Park, C.; Kim, N.H.; Kim, S.H.; Yu, Y.S. Fall-Detection Algorithm Using 3-Axis Acceleration: Combination with Simple Threshold and Hidden Markov Model. J. Appl. Math. 2014, 2014, 896030. [CrossRef]

64. De Quadros, T.; Lazzaretti, A.E.; Schneider, F.K. A Movement Decomposition and Machine Learning-Based Fall Detection System Using Wrist Wearable Device. IEEE Sens. J. 2018, 18, 5082-5089. [CrossRef] 